Review

\title{
Air Quality Response Modeling for Decision Support
}

\section{Daniel S. Cohan ${ }^{1, *}$ and Sergey L. Napelenok ${ }^{2}$}

1 Department of Civil and Environmental Engineering, Rice University, 6100 Main Street MS 519, Houston, TX 77005, USA

2 U.S. Environmental Protection Agency, Research Triangle Park, NC 27711, USA;

E-Mail: napelenok.sergey@epa.gov

* Author to whom correspondence should be addressed; E-Mail: cohan@rice.edu; Tel.: +1-713-348-5129; Fax: +1-713-348-5268.

Received: 20 June 2011; in revised form: 10 August 2011 / Accepted: 17 August 2011 / Published: 26 August 2011

\begin{abstract}
Air quality management relies on photochemical models to predict the responses of pollutant concentrations to changes in emissions. Such modeling is especially important for secondary pollutants such as ozone and fine particulate matter which vary nonlinearly with changes in emissions. Numerous techniques for probing pollutant-emission relationships within photochemical models have been developed and deployed for a variety of decision support applications. However, atmospheric response modeling remains complicated by the challenge of validating sensitivity results against observable data. This manuscript reviews the state of the science of atmospheric response modeling as well as efforts to characterize the accuracy and uncertainty of sensitivity results.
\end{abstract}

Keywords: sensitivity analysis; source apportionment; instrumented models; air quality modeling; review

\section{Introduction}

At their essence, photochemical models are tools for estimating the pollutant concentrations that would result from given emissions, meteorology, and other specified conditions. Those simulated concentrations are critical to forecasting future pollution events, evaluating scientific understanding of emission inventories and atmospheric processes, assessing relationships between source emissions and 
receptor concentrations, and reconstructing atmospheric conditions beyond the limits of available observations. The accuracy of simulated concentrations relative to ambient observations is a primary measure of a photochemical model's performance [1].

However, for policy applications, it is often the responses of concentrations to emission changes, rather than the concentrations themselves, that most critically inform decision making. For example, modeling to demonstrate future attainment of U.S. ambient air quality standards typically compares concentrations under base and proposed future emissions to determine the sufficiency of an attainment plan [2]. Component measures for such plans can be prioritized based on sensitivity modeling of pollutant responsiveness to various emitters [3]. Other applications seek to apportion the origin of pollutant concentrations among precursor sources (source apportionment), or to quantify the benefits of a control policy. In each case, some form of atmospheric response modeling must be used to characterize the responsiveness of concentrations to emissions.

Atmospheric response modeling is especially important for secondary pollutants which form from nonlinear interactions of precursor compounds. Secondary pollutants such as tropospheric ozone and (secondary) particulate matter (PM) have been among the leading targets of air pollution control efforts in recent decades due to their impacts on human health and the natural environment [4,5]. The nonlinear formation of these pollutants [6] necessitates considering spatially and temporally variable meteorological and chemical conditions, typically via three-dimensional photochemical model simulations, to predict concentration responses to emission changes [7]. Other forcings on ambient pollutant concentrations may also be of interest in policy applications, such as responses due to climate change and changes in land use.

A major challenge in atmospheric response modeling is evaluating the accuracy of sensitivity results. While simulated concentrations can be evaluated against observations from satellites, aircraft, and ground-based monitors, the sensitivities of concentrations to emissions are not directly observed. Dynamic evaluation seeks to evaluate concentration-emission relationships within air quality models by considering periods of substantial emission changes [1]. For example, studies may compare simulated and observed changes in pollutant concentrations between weekdays and weekends [8,9], or across multiple years in which substantial emission changes have been documented [10,11]. Still, evaluation of simulated sensitivities is less direct than for concentrations, and is complicated by uncertainties in simulated emissions changes and meteorological variability.

Here, various techniques that have been developed to probe the responses of pollutant concentrations to emissions perturbations in photochemical models, and their use to inform policy applications such as control strategy development and source apportionment are reviewed. Efforts to characterize the accuracy and uncertainty of concentration-emission sensitivity estimates are also reviewed.

\section{Response Modeling Methods}

A wide array of response modeling techniques has been applied to probe relationships between concentrations and emissions in photochemical models. Several of the most widely used methods are described here: brute-force, decoupled direct method, adjoint, and source apportionment. 


\subsection{Brute-Force Method}

The simplest and most widely used method for characterizing concentration response to emissions in a photochemical model is simply to rerun it with alternate emission rates. This "brute-force" (finite difference) method computes differences between concentrations in simulations with base and perturbed rates of emissions or other parameters, typically with other conditions held fixed unless interactions with climate change are being investigated. A key appeal of brute-force is its ready application in any photochemical model, without the substantial programming required to implement the other response modeling techniques.

In some brute-force applications, modelers may construct alternate emission inventories to represent specific scenarios of interest to policy development or scientific investigation. For example, scenarios may represent emission levels under control strategies [12], or under projected climate change [13,14]. Other studies consider hypothetical percentage changes in emissions by species, source sector, or source region [15]. In those cases, it is typically assumed that the rate of concentration change per emission change can be linearly interpolated or extrapolated to predict the impacts of emission changes smaller or larger than the level explicitly modeled. More formally, suppose concentrations $\mathbf{C}_{i}(\mathbf{x}, t)$ are simulated under both base $\left(\tilde{\mathbf{E}}_{i, 0}(\mathbf{x}, t)\right)$ and perturbed $\left(\tilde{\mathbf{E}}_{i, f}(\mathbf{x}, t)\right)$ levels of the emission component of interest, where $\tilde{\mathbf{E}}_{f}$ differs from $\tilde{\mathbf{E}}_{0}$ by fraction $\Delta f$ :

$$
\begin{gathered}
\tilde{\mathbf{E}}_{f} \equiv(1+\Delta f) \tilde{\mathbf{E}}_{0} \\
\mathbf{C}_{0} \equiv \mathbf{C}\left(\tilde{\mathbf{E}}_{0}\right) \\
\mathbf{C}_{f} \equiv \mathbf{C}\left(\tilde{\mathbf{E}}_{f}\right)
\end{gathered}
$$

Notations for species $(i=1, \ldots, \mathrm{N})$, place $(\mathbf{x}=(x, y, z))$, and time $(t)$ are dropped for convenience. The brute-force method would then approximate concentrations $\mathbf{C}_{\varepsilon}$ under any other emission level $\tilde{\mathbf{E}}_{\varepsilon}$ by linearly scaling the difference in concentrations between the perturbed and base simulations:

$$
\begin{gathered}
\tilde{\mathbf{E}}_{\varepsilon} \equiv(1+\Delta \varepsilon) \tilde{\mathbf{E}}_{0} \\
\mathbf{C}_{\varepsilon} \approx \mathbf{C}_{0}+\frac{\Delta \varepsilon}{\Delta f}\left(\mathbf{C}_{f}-\mathbf{C}_{0}\right)
\end{gathered}
$$

For pollutants with a nonlinear response to emission rates, the accuracy of Equation 5 will tend to degrade as the fractional perturbation of interest, $\Delta \varepsilon$, differs more sharply from the explicitly modeled perturbation, $\Delta f$. Specifically, if concentrations exhibit a saturating (concave down) response to precursor emissions as is typically observed for ozone, Equation 5 will tend to overestimate the benefit of emission reductions smaller than $\Delta f$ and underestimate the benefit of larger emission reductions, assuming an emission reduction $(\Delta f<0)$ was simulated in the perturbation case. However, the accuracy of Equation 5 is rarely examined explicitly. Selection of perturbation levels relevant to the policy or scientific questions at hand will tend to enhance the accuracy and usefulness of brute-force results. The accuracy of brute-force sensitivities can also be improved by applying the central difference method shown in Equation 6: 


$$
\mathbf{C}_{\varepsilon} \approx \mathbf{C}_{0}+\frac{\Delta \varepsilon}{2 \Delta f}\left(\mathbf{C}_{f}-\mathbf{C}_{-f}\right)
$$

where $\mathbf{C}_{-f}$ are the concentrations under emission level $\tilde{\mathbf{E}}_{-f}$. However, this approach doubles the needed number of perturbation simulations, and does not address inaccuracies arising from extrapolations to input perturbations substantially larger than $\Delta f$. Furthermore, the brute-force method has been shown to be susceptible to numerical instability due to model discontinuities and roundoff errors [16-18].

Another complication of nonlinear concentration-emission response is that the impacts of perturbations in multiple emission components will not be strictly additive. One approach to represent the joint impacts of simultaneous emission perturbations is response surface modeling [19,20]. Brute-force modeling is conducted for a matrix of perturbation scenarios, each representing different levels of perturbations in the emission components. Statistical analysis of the results is then applied to create a response surface that estimates concentrations for any combination of perturbations in the emission components [19,20]. Response surface modeling was recently applied to characterize the nonlinear response of ozone to precursor emissions in China [21]. Response surfaces also have been validated to be highly accurate in "metamodeling" PM concentrations in an underlying model [20]. However, as is true for brute-force methods generally, response surfaces require a computationally burdensome number of model simulations when many input perturbations are of interest.

\subsection{Decoupled Direct Method}

Various approaches have attempted to avert the need for differencing numerous brute-force simulations by computing pollutant sensitivities directly within the photochemical model. Several approaches, including the coupled direct method and Green's function method have been found to be unstable or impractical for use in comprehensive photochemical models (see Yang et al. [22] and references therein). However, the decoupled direct method (DDM) [23] and adjoint sensitivity analysis [24] have been shown to stably and efficiently compute sensitivity relationships and thus have been more widely implemented in three-dimensional models [16,17,22,25-28].

DDM operates by tracking sensitivity coefficients of all concentrations to specified model inputs or parameters, utilizing equations derived from those representing concentrations in the underlying model to evolve sensitivities. The atmospheric diffusion equation (ADE) representing the transport and reactions of chemical compounds in photochemical models can be written in simplified form as:

$$
\frac{\partial \mathbf{C}}{\partial t}=-\nabla(\mathbf{u} \mathbf{C})+\nabla(\mathbf{K} \nabla \mathbf{C})+\mathbf{R}+\mathbf{E}+\cdots
$$

where $\mathbf{u}(\mathbf{x}, t)$ is the wind field, $\mathbf{K}(\mathbf{x}, t)$ is the turbulent diffusivity tensor, $\mathbf{R}_{i}(\mathbf{x}, t)$ are the net rates of chemical production, $\mathbf{E}_{i}(\mathbf{x}, t)$ are the emission rates, and the ellipsis denote other processes represented by the model. The ADE is solved by operator splitting and is subject to initial and boundary conditions described elsewhere [29].

Suppose that we are interested in how concentrations vary with perturbations in targeted model inputs or parameters $P_{j}(\mathbf{x}, t)$, which may be perturbed from their unperturbed values $P_{j}$ by scaling factors $\varepsilon_{j}$, analogously to Equation 4 : 


$$
p_{j}=\varepsilon_{j} P_{j}=\left(1+\Delta \varepsilon_{j}\right) P_{j}
$$

Since our interest here is in sensitivities to emissions, note that each parameter $p_{j}$ is equivalent to an emission component $\tilde{\mathbf{E}}$ in the notation of the previous section.

Semi-normalized sensitivity coefficients $\mathbf{S}_{i, j}^{(1)}(\mathbf{x}, t)$ of concentration response to $p_{j}$ are developed by scaling non-normalized local sensitivity coefficients $\left(\partial \mathbf{C} / \partial P_{j}\right)$ by the unperturbed value $P_{j}$ of the parameter:

$$
\mathbf{S}_{j}^{(1)}=P_{j} \frac{\partial \mathbf{C}}{\partial p_{j}}=P_{j} \frac{\partial \mathbf{C}}{\partial\left(\varepsilon_{j} P_{j}\right)}=\frac{\partial \mathbf{C}}{\partial \varepsilon_{j}}
$$

This semi-normalization simplifies calculations by placing sensitivity coefficients into the same units as concentrations. For the case of sensitivity to emission rates, DDM computes the evolution of $\mathbf{S}_{j}^{(1)}$ by substituting Equation 9 into Equation 7, yielding the equation below [22,27]:

$$
\frac{\partial \mathbf{S}_{j}^{(1)}}{\partial t}=-\nabla\left(\mathbf{u} \mathbf{S}_{j}^{(1)}\right)+\nabla\left(\mathbf{K} \nabla \mathbf{S}_{j}^{(1)}\right)+\mathbf{F}_{i} \mathbf{S}_{j}^{(1)}+\tilde{\mathbf{E}}_{j}+\cdots
$$

where $\mathbf{F}$ is the Jacobian matrix $\left(F_{i k}=\partial R_{i} / \partial C_{k}\right)$ and $\tilde{\mathbf{E}}_{j}$ is the base level of the emissions inventory component represented by sensitivity parameter $p_{j}$. Alternate terms for representing sensitivities to parameters other than emissions, as well as initial and boundary conditions for Equation 10, are described in other references $[22,26]$. DDM is a decoupled approach in that for each process sensitivities are updated separately from, and after, concentrations.

Slightly different approaches have been taken to implement Equation 10 in air quality models. The original DDM formulation of Dunker [23,30] applies the same algorithms and internal time steps for chemistry in Equations 6 and 9, whereas the "DDM-3D" variation of Yang et al. [22] factorizes the Jacobian only once per advection time step. The former approach maximizes the accuracy and consistency of sensitivity results, whereas the latter enhances computational efficiency. Nevertheless, successful implementations of both DDM [26,31] and DDM-3D [18,22,25,27,31,32] in state-of-the-science photochemical models have been validated to yield computational savings and consistent results relative to brute-force.

A key distinction between DDM and brute-force is that DDM predicts local sensitivity coefficients $\frac{\partial \mathbf{C}}{\partial \varepsilon_{j}}$, representing responsiveness to infinitesimal changes in a parameter, whereas brute-force predicts responses to finite changes, $\frac{\Delta \mathbf{C}}{\Delta \varepsilon}$. Just as the accuracy of brute-force results may degrade as interpolated or extrapolated beyond the explicitly modeled perturbation level, linear scaling of local first-order DDM sensitivities may poorly represent the nonlinear impacts of large perturbations. Thus, for highly nonlinear relationships, first-order DDM results can be applied reliably only to characterize local responsiveness or the impacts of small perturbations.

Hakami et al. [27,33] showed that the applicability of DDM can be greatly expanded by incorporating second-order sensitivity coefficients. Their High-order Decoupled Direct Method (HDDM) extended the DDM-3D algorithms to compute second-order or even higher-order sensitivity 
coefficients. Second-order self-sensitivity coefficients $\mathbf{S}_{j, j}^{(2)}=\frac{\partial^{2} \mathbf{C}}{\partial \varepsilon_{j}^{2}}$ represent the curvature of concentration response to a single parameter, whereas cross-sensitivity coefficients $\mathbf{S}_{j, k}^{(2)}=\frac{\partial^{2} \mathbf{C}}{\partial \varepsilon_{j} \partial \varepsilon_{k}}$ characterize how sensitivity of concentrations to one parameter changes as a second parameter is varied.

Validation tests confirmed the consistency of HDDM and brute-force finite differencing in estimating second-order local sensitivities [27,33]. More significantly, Hakami et al. showed that Taylor series expansions incorporating first- and second-order HDDM coefficients via the equation below can reliably predict ozone response to simultaneous large percentage (e.g., 50\%) changes in multiple parameters $[27,33]$ :

$$
\mathbf{C}_{\varepsilon_{j}, \varepsilon_{k}} \approx \mathbf{C}_{0}+\Delta \varepsilon_{j} \mathbf{S}_{j}^{(1)}+\Delta \varepsilon_{k} \mathbf{S}_{k}^{(1)}+\frac{\Delta \varepsilon_{j}^{2}}{2} \mathbf{S}_{j}^{(2)}+\frac{\Delta \varepsilon_{k}^{2}}{2} \mathbf{S}_{k}^{(2)}+\Delta \varepsilon_{j} \Delta \varepsilon_{k} \mathbf{S}_{j, k}^{(2)}
$$

where $\mathbf{C}_{\varepsilon_{j}, \varepsilon_{k}}$ denotes concentrations when parameters $P_{j}$ and $P_{k}$ are perturbed by fractions $\Delta \varepsilon_{j}$ and $\Delta \varepsilon_{k}$ respectively. Cohan et al. [25] showed that Equation 11 could even be extended with reasonable accuracy to predict the ozone impacts of zeroing-out individual emission sources (i.e., $\Delta \varepsilon_{j}=-1$ ), providing results closer to source apportionment. While studies applying Equation 11 with HDDM for ozone have proliferated (e.g., [34-36]), no published study has yet extended DDM to second-order for PM, although such an extension was recently described in a conference presentation [37].

The majority of DDM applications have focused on the response of pollutant concentrations to emission changes. These include quantifications and optimizations of emission control strategy impacts, in some cases linked with consideration of control costs [38], health effects [39], or climate change [40]. Hakami et al. [33] showed that HDDM coefficients could be applied to generate isopleths of ozone response to simultaneous changes in $\mathrm{VOC}$ and $\mathrm{NO}_{\mathrm{x}}$ emissions. DDM-computed sensitivities to emissions have also been applied through a variety of approaches to conduct inverse modeling of emission inventories [41-43]. Sensitivities to reaction rate constants have been applied to assess key reactions and uncertainties in the chemical mechanisms that drive air quality models [44,45]. All of these applications, though achievable using brute-force methods, benefitted from the ability of DDM to efficiently compute sensitivities to numerous input parameters.

\subsection{Adjoint}

Brute-force and DDM each compute the sensitivities of all model outputs throughout the domain to specified model inputs and parameters. Thus, they are well-suited for characterizing how concentrations or deposition amounts everywhere are impacted by a limited number of changes in emissions or other parameters of interest. However, for some applications, it may be desired to probe how specific model outputs are influenced by numerous model parameters. For example, one may seek to probe how pollutant concentrations or deposition rates at a single monitor are influenced by many model parameters, or how a spatially aggregated metric of pollutant conditions is influenced by numerous emitters. As the number of emitters or input parameters of interest grows, it would quickly become cumbersome to compute forward sensitivities to each parameter. 
For cases such as these, an adjoint of a model provides an efficient method for calculating sensitivity of a few model outputs to numerous model parameters. Adjoints have been implemented to some extent in several modern regional and global photochemical models including CMAQ [16], CHIMERE [46], STEM [47], GEOS-Chem [17], and others. Adjoints of atmospheric models have been used in a variety of applications including attainment studies of ozone in specific airsheds as well as for ozone and $\mathrm{PM}_{2.5}$ on continental scales [28,48,49]; inverse modeling of black carbon based on ground and ship measurements [50]; long-range transport of ozone [51] and black carbon [52]; and data assimilation of ozone and $\mathrm{NO}_{\mathrm{x}}$ measurements [47].

Mathematical description of an adjoint is simplified by introducing the forward tangent linear model (TLM), which is analogous to the formulation of DDM (Equation 10). Both DDM and TLM refer to the forward method for calculating sensitivity because the perturbation is carried forward through the various model processes and in time.

The ADE in operator form would be:

$$
\mathbf{C}=\mathbf{M}(\mathbf{p})
$$

where the model output vector $\mathbf{C}$ is a function of the model input parameter vector $\mathbf{p}$, and $\mathbf{M}$ is the operator matrix representing the combination of all processes in the model.

Analogously, TLM (Equation 10) in operator form can be written as:

$$
\delta \mathbf{C}=\mathbf{L}(\delta \mathbf{p})
$$

where $\mathbf{L}$ is the Jacobian of the model operator. Furthermore, specific adjoint applications require the definition of a scalar function, $J$, based on model outputs as:

$$
J=J(\mathbf{C})
$$

In a simple application of calculating a sensitivity field of species $i, J=c_{i}$, whereas in a more complex scenario of inverse modeling, $J$ can be a cost function dependent on the difference between modeled and observed values, the difference between initial and perturbed parameters, the observation error covariance matrix, and possibly other terms [17]. The goal of the adjoint would then be to efficiently determine $\partial J / \partial \boldsymbol{p}$, or $\partial c_{i} / \partial \boldsymbol{p}$ in the simplest case.

Similar to DDM sensitivities (Equation 9), it is possible to define the adjoint variable $\boldsymbol{\lambda}_{\boldsymbol{i}}$ as:

$$
\lambda_{i}=\frac{\partial J}{\partial p_{i}}
$$

Then the adjoint can be defined by applying Lagrange multipliers to Equation 10 and integrating by parts by taking into account its initial and boundary conditions [47] as:

$$
\frac{\partial \lambda_{i}}{\partial t}=-\nabla\left(\mathbf{u} \lambda_{i}\right)-\nabla\left(\mathbf{K} \nabla \lambda_{i}\right)-\mathbf{F}_{i}^{\mathrm{T}} \lambda-\varphi_{i}
$$

where $\varphi_{i}$ is the forcing term dependent on specific application and the definition of $J$.

In practice, adjoint functions are applied to each model process in sequence, including advection, diffusion, chemistry, and aerosol processes. Two methods exist for adjoint implementation. If the underlying functions describing a particular process are differentiable and can be used directly, then a continuous adjoint for that process is possible. A continuous adjoint for a particular process is 
constructed by differentiating the underlying mathematical equations first and then discretizing the adjoint equations of solution. On the other hand, if such calculations are too cumbersome or impossible due to the complexity of the process, then the process can be numerically discretized first and later differentiated to obtain a discrete adjoint. The advantage of the continuous adjoint is that it obtains an exact solution that may be more useful in interpreting the results, because it represents a physical time-dependent sensitivity behavior and explicitly assures numerical stability [53]. In contrast, a discrete adjoint may exhibit instability and yield a solution inconsistent with the forward model [54]. However, the attraction of a discrete adjoint is that it can often be derived using automatic differentiation tools that process the forward model code directly. Furthermore, discrete adjoint results may be more easily validated, because the resulting gradients do not differ from the actual gradient of the numerical cost function as can be the case with continuous adjoints [17]. In practice, both approaches are frequently used for an adjoint implementation within a particular forward model that is solved using operator splitting, where one method may be used for transport processes and another for chemistry.

Hakami et al. [48] demonstrate a potential regulatory application of adjoint modeling to calculate sensitivities of a nationwide U.S. ozone national ambient air quality standard (NAAQS) to precursor emissions of $\mathrm{NO}_{\mathrm{x}}$ and VOCs. The sensitivities are presented varying in space and time to provide a fully resolved source/receptor relationship for modeled ozone nonattainment. Source categories and locations with the greatest impact are quickly identified as potential targets of control strategies.

\subsection{Source Apportionment}

Source apportionment seeks to quantify the contributions of various emission sources from specific geographic areas or emissions sources to pollutant levels at particular locations. While source apportionment in photochemical models may be conducted by a brute-force method zeroing out sources one by one, this may become computationally prohibitive if many emitters are of interest. Thus, a host of tools has been implemented to enable more efficient probing of source apportionment relationships in air quality models. Here, we focus solely on model-based source apportionment techniques, not on the wide array of observation-based source apportionment techniques such as chemical mass balance and positive matrix factorization [55] that characterize source contributions based on ambient data.

Apportioned fractions of species are typically tracked separately from base concentrations with the specific intent to not alter base model predictions. Source apportionment methods are typically less computationally costly than zero-out brute-force simulations, but can be limiting in that they only track a subset of all possible source and species combinations. Typically, end-point pollutants include either ozone or various chemical components of particulate matter, but rarely in the same model. These methods consider secondary formation from precursor emissions of nitrogen oxides $\left(\mathrm{NO}_{\mathrm{x}}=\mathrm{NO}\right.$ and $\left.\mathrm{NO}_{2}\right)$, volatile organic compounds (VOCs), sulfur dioxide $\left(\mathrm{SO}_{2}\right)$, and ammonia $\left(\mathrm{NH}_{3}\right)$, in addition to primary emissions of the tracked species. Usually, boundary and initial conditions are also tracked separately.

Various approaches have been taken in recent years to develop source apportionment methods. These methods are generally designed to provide information of pollutant formation from predefined geographic regions and/or chemical precursors. One approach for resolving emissions source 
attribution for PM species is to model the particles as an explicit external mixture while preserving source information [56]. In this method, particulate matter precursors from each source are injected into the model separately and their identity is preserved as they undergo the various physical and chemical transformations. Modifications to the underlying chemical mechanism and the accompanying solver are required to accommodate precursor species duplication. A similar approach has been demonstrated for resolving ozone formation from tagged VOC sources [57]. Again, modifications to the chemistry module are required, but in this case, tracking contributions of different emissions sources to concentrations of various VOCs, alkoxy radical (RO), peroxy radical $\left(\mathrm{RO}_{2}\right)$, and hydroperoxyl radical $\left(\mathrm{HO}_{2}\right)$ is considered. These species dictate the conversion rate of $\mathrm{NO}$ to $\mathrm{NO}_{2}$, which in turn is used as the indicator for ozone formation.

Source apportionment implementation for PM and ozone is complicated by the interaction of second-generation products from explicitly tagged precursors with one another. Such cases are typically handled on a reaction by reaction basis and the products are attributed to sources according to the linkage established through their molecular structure.

Source oriented methods are computationally demanding, because they greatly increase not only the number of species transported by the model, but also the computational burden involved in solving a larger number of potentially stiff differential equations governing gas and aerosol chemical interactions. However, preserving emissions information through the model helps to overcome one of the main challenges of source apportionment, which is accounting for the highly nonlinear and time variant nature of secondary pollutant formation. Computationally lighter versions of this method track only a subset of species. For example, the carbon apportionment model has been used as a diagnostic tool to track sources of chemically inert particulate organic and elemental carbon $[58,59]$.

Other source apportionment techniques rely on simplifying assumptions to reduce the size of the numerical problem. For example, the ozone source apportionment technology (OSAT) [60] implemented within the Comprehensive Air quality Model with extensions (CAMx) [61] groups emissions of $\mathrm{NO}_{\mathrm{x}}$ and VOCs from each tracked source together with the corresponding ozone formed as the result of these emissions into families, and tracks these families through the various processes in the air quality model. OSAT adds the flexibility of apportioning ozone to $\mathrm{NO}_{\mathrm{x}}$ emissions in addition to VOCs, and does so by determining $\mathrm{NO}_{\mathrm{x}}$ - or VOC-limiting ozone formation regimes on the basis of the ratio of the production of peroxide $\left(\mathrm{H}_{2} \mathrm{O}_{2}\right)$ to the production of nitric acid $\left(\mathrm{HNO}_{3}\right)$ [62]. At ratios above 0.35 , the ozone formed is assigned to emissions of $\mathrm{NO}_{\mathrm{x}}$, and at ratios below 0.35 the ozone formed is assigned to emissions of VOCs. This method still accounts for different VOC reactivity as do the explicit tracking methods, but may have some limitations during instances where ozone is titrated through reaction with $\mathrm{NO}$ near large emissions sources of $\mathrm{NO}_{\mathrm{x}}$, since instantaneous negative apportionment is not possible.

As a variation on OSAT, the anthropogenic precursor culpability assessment (APCA) [61] has been implemented in the CAMx model. APCA functions similarly to OSAT, but reallocates the ozone production that was attributed to non-controllable sources to the controllable precursor that participated in its formation. For example, in a situation where OSAT would attribute ozone production to biogenic emissions of VOCs, APCA would reassign the attribution to anthropogenic $\mathrm{NO}_{\mathrm{x}}$ even under VOC-limiting conditions. As such, this method biases towards assigning more ozone formation to $\mathrm{NO}_{\mathrm{x}}$ emissions, in order not to assign culpability to presumably non-controllable biogenics. 
Also stemming from the development of OSAT in CAMx is the particulate matter source apportionment technology (PSAT) and its complement, online particulate source apportionment (OPSA) [63]. Both of these methods track primary and secondary PM components by making the simplifying assumption that each secondary component links directly to one specific precursor. For example, $\mathrm{NO}_{\mathrm{x}}$ emissions lead directly to formation of particulate nitrate. Secondary effects, such as the nonlinear chemical and thermodynamic interactions between species are considered through the behavior of the bulk, non-apportioned species based only on the equilibrium assumption. Both PSAT and OPSA start with the gas-phase OSAT implementation to which PM relevant reactions are added. PSAT differs from OPSA in that it apportions the transport of the tagged species based on fluxes of the bulk in an offline way, instead of transporting the tagged species themselves as in OPSA. This introduces some error to the system, since the PSAT attributes the fluxes linearly to save on computational time spent on transport routines.

The CMAQ model also has implemented methodology for particulate source apportionment in the way of tagged species source apportionment (TSSA), which tracks precursors to aerosol sulfate, nitrate, ammonium, elemental carbon, secondary organic aerosol, and other aerosol species [64]. Similar to the PSAT implementation in CAMx [63], this method also applies information from bulk species for most model transformations to the tagged species. However, gaseous chemistry is described more explicitly by modifying the underlying chemical mechanism and adding chemical tracers relevant for aerosol formation. TSSA also employs mass normalization routines that ensure mass conservation, as do OSAT, APCA, and PSAT. This is done by introducing an "other" source category automatically as a tracer in addition to user specified geographical and chemical precursor sources.

An important consideration for interpreting results of any air quality source apportionment method is that there is no unique true answer to attributing pollutant concentrations to precursor sources. The contributions of various sources may not be strictly additive, since photochemical regime and pollutant responsiveness may change as emission rates vary. The emission source assigned the greatest zero-out source contribution may not necessarily yield the most benefit from its incremental control, and its contribution may vary as other sources are controlled. However, source apportionment results still provide a wealth of information for the purpose of control strategy development or culpability assessment.

Other drawbacks of source apportionment techniques come from the fact that these methods try to strike a balance between computational efficiency and explicit treatment of all science processes done by the base model. Ozone source apportionment techniques frequently make use of various assumptions to calculate whether or not the ozone producing regime is either $\mathrm{NO}_{\mathrm{x}^{-}}$or VOC-limited. Apportionment of inorganic particulate species is frequently done by ignoring or simplifying thermodynamic interactions between PM species. Most of the described apportionment techniques assume that secondary PM components are linked directly to one precursor species. For example, secondary sulfate is traced back only to $\mathrm{SO}_{\mathrm{x}}$ emissions. Therefore, these methods are unable to capture indirect effects such as the replacement of ammonium sulfate with ammonium nitrate that sometimes accompanies reductions of $\mathrm{SO}_{2}$ emissions [65], or the influences of atmospheric oxidants and their precursors on secondary organic aerosol formation [66].

Similar to the other response models discussed, source apportionment techniques aim to generate additional information about one or more modeling episodes that could be used to test changes to the forcings behind the model resolved state of air quality without the need for additional simulation. One 
such application is detailed by Baker and Foley [67]. In their approach, the CAMx model with PSAT is used to estimate annual sulfate and nitrate formation from emissions of precursors from 99 power plants in the eastern United States. Emissions from these plants were manually perturbed, and the apportionment model repeated to arrive at brute-force sensitivity of source apportionment. Finally, a nonlinear regression model was used to describe the relationship of downwind particulate matter concentrations to emissions strength and distance from source. This hybrid formulation of two response techniques (brute-force and PSAT) together with a statistical model allows for quick approximation for impacts of varying emissions at particular facilities or siting a new facility in the modeling domain.

\section{Accuracy and Uncertainty of Atmospheric Response Estimates}

Given the critical role of atmospheric response modeling in informing air quality decision-making, the accuracy and uncertainty of response estimates are important to examine. All of the instrumented modeling techniques above can be validated against the forward model response to ensure that they faithfully represent pollutant-emission response within the underlying model. Most validations of DDM have shown it to be highly accurate in capturing pollutant response to small-scale emission changes. The extent local sensitivity coefficients can predict large-scale response depends on the nonlinearity of pollutant formation under the conditions at hand; in some situations, first-order sensitivities may be sufficient to predict response for up to $\pm 30 \%$ changes in emissions $[31,68]$, whereas Taylor expansions including second-order HDDM coefficients can allow accurate representation of ozone response to domain-wide emission reduction of at least 50\% [25,33].

Such validations assess whether a response modeling technique is reliably capturing relationships within the underlying model, but do not address the accuracy of the model itself in representing actual atmospheric response to emission changes. Simulated pollutant concentrations are routinely evaluated against observations [1], but pollutant-emission sensitivities are not directly measured. While consistency of simulated and observed concentrations lends confidence to model performance, it does not guarantee the accuracy of sensitivity and source apportionment results. Different models or alternate settings of a single model can achieve similar performance for pollutant concentrations despite yielding markedly different predictions of pollutant-emission response $[44,69,70]$. Thus, there is growing interest in the use of observational data to infer pollutant responsiveness to emission changes and thereby ground truth modeled sensitivity results. The approaches described in the following three paragraphs - dynamic evaluation, observational indicator ratios, and receptor-based source apportionment-provide informative though imperfect gauges of response modeling accuracy, as each of these methods entails its own set of assumptions and simplifications.

Dynamic evaluation assesses the ability of models to represent changes in pollutant concentrations resulting from changes in emissions or other conditions [1]. For example, differences in pollutant concentrations on weekdays and weekends can be used to assess their responsiveness to weekly patterns in emission rates $[8,9,71]$. Other dynamic evaluation studies have considered how pollutant levels have responded to long-term trends in emission rates, such as those resulting from major emission control policies $[10,11,72]$. In each case, a key challenge is to accurately characterize the changes in emission rates and meteorological conditions across the periods of interest, so that the 
pollutant response can be effectively isolated. However, since characterizations of emission trends and meteorology are inevitably imperfect, dynamic evaluation cannot definitively determine whether mispredicted trends in concentrations arise from those imperfections or from errors in a model's responsiveness.

Another check on modeled sensitivities is provided by observational indicator ratios, which consider ambient measurements of various species to infer how ozone or secondary PM was formed. For example, ratios of species concentrations such as $\mathrm{O}_{3} / \mathrm{NO}_{\mathrm{y}}\left(\mathrm{NO}_{\mathrm{y}}=\mathrm{NO}_{\mathrm{x}}\right.$ and its oxidation products) and $\mathrm{H}_{2} \mathrm{O}_{2} / \mathrm{HNO}_{3}$ have been found to be effective indicators of whether ozone formed under $\mathrm{NO}_{\mathrm{x}^{-}}$or VOC-limited conditions [62,73]. More quantitative estimates of ozone responsiveness to $\mathrm{NO}_{\mathrm{x}}$ emissions can be obtained from ozone production efficiency metrics, which quantify the number of ozone molecules produced per molecule of $\mathrm{NO}_{\mathrm{x}}$ consumed [74]. For PM, the observed ratio between free ammonia and total nitrate concentrations may indicate whether formation of wintertime nitrate is limited primarily by $\mathrm{NO}_{\mathrm{x}}$ or ammonia emissions [75]. Such indicator ratios already have a role in some source apportionment methods, but could be used further for evaluation purposes.

For source apportionments, various receptor-based methods such as positive matrix factorization and chemical mass balance have been developed for apportioning PM based on observations of its constituent compounds [76-78]. Some studies have attempted to compare PM source apportionments derived from receptor-based and emission-based models [79], or to develop hybrid approaches combining the two methods [80]. Whereas source signatures can be inferred from speciated PM data, such approaches are, of course, inapplicable to ozone and other individual gases.

Apart from comparisons with observational data to gauge accuracy of response modeling, a separate line of efforts has sought to characterize the uncertainty in response modeling that arises due to uncertain model inputs and formulations. Parametric uncertainties result from uncertain model input data and parameters, whereas structural uncertainties result from imperfect numerical formulations of physical and chemical processes [81]. Most studies conducted numerous brute-force runs with Monte Carlo sampled inputs to characterize changes in pollutant-emission sensitivities resulting from changes in uncertain inputs [82-84]. More recent studies have introduced methods utilizing HDDM and adjoints for more efficient uncertainty characterization [85-88]. In either case, Bayesian approaches could be applied to use observational data to assess the relative likelihoods of various plausible simulations and thereby refine uncertainty estimates $[89,90]$.

\section{Discussion}

The use of response modeling methods in air quality management has increased over recent years partly due to significant improvements to the computational capacity of management agencies, and partly due to the need to find more creative control strategies in response to lower air quality standards. While new probing tools continue to be introduced and refined, a growing number of publications apply existing techniques to new air quality challenges.

As applications of response modeling proliferate through a wider community of users, care must be taken to ensure that the methods are applied and interpreted in an effective manner. The use of brute-force methods tends to be straightforward. More complex methods such as DDM or adjoint modeling typically require more extensive validation to ensure that results are consistent with the 
forward model, both to protect against possible coding errors as well as to check the method's performance in a new photochemical regime. For all methods, proper interpretation of results is crucial. For example, extrapolations of local sensitivity coefficients or interpolations of large-scale impacts can introduce error when response is highly nonlinear. There may also be important interactions between responses not captured by sensitivities to individual parameters. Response surface modeling and high-order sensitivity coefficients can each provide accurate results across a range of emission perturbations, but can be more complex to apply than other methods.

The results of multiple response modeling methods can be highly complementary. For example, source apportionment computes the impacts of entire emission sources, whereas DDM characterizes sensitivities to incremental perturbations. Nevertheless, most studies apply only a single response modeling method, despite a handful of studies that have rigorously compared multiple methods [91,92]. Zhang et al. [92] showed that first-order DDM effectively simulated ozone response to $\mathrm{NO}_{\mathrm{x}}$ and VOC emission changes of less than $40 \%$; OSAT was better able to simulate source apportionment (i.e., 100\% emission reductions), but its non-negativity failed to represent VOC-limited regions where reductions in $\mathrm{NO}_{\mathrm{x}}$ may lead to increases in ozone concentrations. Koo et al. [91] compared the results of brute-force, PSAT, and DDM characterizations of particulate matter sensitivity and source apportionment. They found that first-order DDM could simulate responses of inorganic secondary aerosols to emissions perturbations of $20 \%$ or more, and of organic and primary aerosols to up to $100 \%$. PSAT yielded similar results to zero-out source apportionment in most cases, but did not account for indirect effects such as when removal of an $\mathrm{SO}_{2}$ emitter frees up oxidants to react with $\mathrm{SO}_{2}$ from other sources.

The response modeling methods reviewed here characterize the responses of pollutants to emission changes, but do not necessarily explain the physical or chemical causes of those responses. Other techniques such as process analysis [93] characterize the contributions of various physical and chemical processes to pollutant concentrations and formation and destruction rates. Process analysis has been applied most frequently to quantify the processes influencing tropospheric ozone [94-96]. Additional insights into the causes of atmospheric response can be gleaned by substituting alternate mechanisms or parameterizations in air quality models. Ultimately, response probing methods can perform only as well as the underlying model, so ongoing improvements to the physical and chemical representations in atmospheric models, and the scientific understanding that underpins them, remain paramount.

\section{Acknowledgements}

The work of Cohan was supported by National Science Foundation CAREER Award Grant 087386. Although this manuscript has been reviewed and approved for publication, it does not necessarily reflect the policy or views of the U.S. Environmental Protection Agency. The authors would like to thank Kirk Baker for helpful input on the manuscript. 


\section{References}

1. Dennis, R.; Fox, T.; Fuentes, M.; Gilliland, A.; Hanna, S.; Hogrefe, C.; Irwin, J.; Rao, S.T.; Scheffe, R.; Schere, K.; et al. A framework for evaluating regional-scale numerical photochemical modeling systems. Environ. Fluid Mech. 2010, 10, 471-489.

2. US-EPA. Guidance on the use of models and other analyses for demonstrating attainment of air quality goals for ozone, PM2.5, and regional haze. EPA-454/B-07-002. April 2007.

3. Cohan, D.S.; Boylan, J.W.; Marmur, A.; Khan, M.N. An integrated framework for multipollutant air quality management and its application in Georgia. Environmen. Manag. 2007, 40, 545-554.

4. Brunekreef, B.; Holgate, S.T. Air pollution and health. Lancet 2002, 360, 1233-1242.

5. Fuhrer, J. Ozone impacts on vegetation. Ozone Sc. Eng. 2002, 24, 69-74.

6. Lin, X.; Trainer, M.; Liu, S.C. On the nonlinearity of the tropospheric ozone production. J. Geophys. Res. 1988. 93,15879-15888.

7. Russell, A.G. Regional photochemical air quality modeling: Model formulations, history, and state of the science. Annu. Rev. Energy Environ. 1997, 22, 537-588.

8. Altshuler, S.L.; Arcado, T.D.; Lawson, D.R. Weekday vs. Weekend ambient ozone concentrations-Discussion and hypotheses with focus on Northern California. J. Air Waste Manag. Assoc. 1995, 45, 967-972.

9. Pierce, T.; Hogrefe, C.; Rao, S.T.; Porter, P.S.; Ku, J.Y. Dynamic evaluation of a regional air quality model: Assessing the emissions-induced weekly ozone cycle. Atmos. Environ. 2010, 44, 3583-3596.

10. Gilliland, A.B.; Hogrefe, C.; Pinder, R.W.; Godowitch, J.M.; Foley, K.L.; Rao, S.T. Dynamic evaluation of regional air quality models: Assessing changes in O-3 stemming from changes in emissions and meteorology. Atmos. Environ. 2008, 42, 5110-5123.

11. Hogrefe, C.; Civerolo, K.L.; Hao, W.; Ku, J.Y.; Zalewsky, E.E.; Sistla, G. Rethinking the assessment of photochemical modeling systems in air quality planning applications. J. Air Waste Manag. Assoc. 2008, 58, 1086-1099.

12. Roth, P.M.; Reynolds, S.D.; Tesche, T.W. Air quality modeling and decisions for ozone reduction strategies. J. Air Waste Manag. Assoc. 2005, 55, 1558-1573.

13. Tagaris, E.; Manomaiphiboon, K.; Liao, K.J.; Leung, L.R.; Woo, J.H.; He, S.; Amar, P.; Russell, A.G. Impacts of global climate change and emissions on regional ozone and fine particulate matter concentrations over the United States. J. Geophys. Res. Atmos. 2007, 112, doi: $10.1029 / 2006 j \mathrm{j} 008262$.

14. Tao, Z.N.; Williams, A.; Huang, H.C.; Caughey, M.; Liang, X.Z. Sensitivity of U.S. surface ozone to future emissions and climate changes. Geophys. Res. Lett. 2007, 34, doi:10.1029/2007GL029455.

15. Roselle, S.J.; Schere, K.L. Modeled response of photochemical oxidants to systematic reductions in anthropogenic volatile organic-compound and $\mathrm{no}_{\mathrm{x}}$ emissions. J. Geophys. Res. Atmos. 1995, 100, 22929-22941.

16. Hakami, A.; Henze, D.K.; Seinfeld, J.H.; Singh, K.; Sandu, A.; Kim, S.T.; Byun, D.W.; Li, Q.B. The adjoint of CMAQ. Environ. Sci. Technol. 2007, 41, 7807-7817. 
17. Henze, D.K.; Hakami, A.; Seinfeld, J.H. Development of the adjoint of GEOS-Chem. Atmos. Chem. Phys. 2007, 7, 2413-2433.

18. Napelenok, S.L.; Cohan, D.S.; Hu, Y.T.; Russell, A.G. Decoupled direct 3D sensitivity analysis for particulate matter (DDM-3D/PM). Atmos. Environ. 2006, 40, 6112-6121.

19. Hill, J.; Polasky, S.; Nelson, E.; Tilman, D.; Huo, H.; Ludwig, L.; Neumann, J.; Zheng, H.C.; Bonta, D. Climate change and health costs of air emissions from biofuels and gasoline. Proc. Natl. Acad. Sci. USA 2009, 106, 2077-2082.

20. US-EPA. Technical Support Document for the proposed PM NAAQS Rule: Response Surface Modeling. February 2006.

21. Xing, J.; Wang, S.X.; Jang, C.; Zhu, Y.; Hao, J.M. Nonlinear response of ozone to precursor emission changes in China: A modeling study using response surface methodology. Atmos. Chem. Phys. 2011, 11, 5027-5044.

22. Yang, Y.J.; Wilkinson, J.G.; Russell, A.G. Fast, direct sensitivity analysis of multidimensional photochemical models. Environ. Sci. Technol. 1997, 31, 2859-2868.

23. Dunker, A.M. The decoupled direct method for calculating sensitivity coefficients in chemical kinetics. J. Chem. Phys. 1984, 81, 2385-2393.

24. Elbern, H.; Schmidt, H.; Ebel, A. Variational data assimilation for tropospheric chemistry modeling. J. Geophys. Res. Atmos. 1997, 102, 15967-15985.

25. Cohan, D.S.; Hakami, A.; Hu, Y.T.; Russell, A.G. Nonlinear response of ozone to emissions: Source apportionment and sensitivity analysis. Environ. Sci. Technol. 2005, 39, 6739-6748.

26. Dunker, A.M.; Yarwood, G.; Ortmann, J.P.; Wilson, G.M. The decoupled direct method for sensitivity analysis in a three-dimensional air quality model-Implementation, accuracy, and efficiency. Environ. Sci. Technol. 2002, 36, 2965-2976.

27. Hakami, A.; Odman, M.T.; Russell, A.G. High-order, direct sensitivity analysis of multidimensional air quality models. Environ. Sci. Technol. 2003, 37, 2442-2452.

28. Martien, P.T.; Harley, R.A. Adjoint sensitivity analysis for a three-dimensional photochemical model: Application to Southern California. Environ. Sci. Technol. 2006, 40, 4200-4210.

29. Mcrae, G.J.; Goodin, W.R.; Seinfeld, J.H. Development of a 2nd-generation mathematical model for urban air pollution. 1. Model formulation. Atmos. Environ. 1982, 16, 679-696.

30. Dunker, A.M. Efficient calculation of sensitivity coefficients for complex atmospheric models. Atmos. Environ. Part A 1981, 15, 1155-1161.

31. Koo, B.; Dunker, A.M.; Yarwood, G. Implementing the decoupled direct method for sensitivity analysis in a particulate matter air quality model. Environ. Sci. Technol. 2007, 41, 2847-2854.

32. Napelenok, S.L.; Cohan, D.S.; Odman, M.T.; Tonse, S. Extension and evaluation of sensitivity analysis capabilities in a photochemical model. Environ. Model. Softw. 2008, 23, 994-999.

33. Hakami, A.; Odman, M.T.; Russell, A.G. Nonlinearity in atmospheric response: A direct sensitivity analysis approach. J. Geophys. Res. Atmos. 2004, 109, doi: 10.1029/2003JD004502.

34. Jin, L.; Tonse, S.; Cohan, D.S.; Mao, X.L.; Harley, R.A.; Brown, N.J. Sensitivity analysis of ozone formation and transport for a central California air pollution episode. Environ. Sci. Technol. 2008, 42, 3683-3689.

35. Kim, S.; Cohan, D.S.; Byun, D.W. Contributions of inter- and intra-state emissions to ozone over Dallas-Fort Worth, Texas. Civ. Eng. Environ. Syst. 2009, 26, 103-116. 
36. Xiao, X.; Cohan, D.S.; Byun, D.W.; Ngan, F. Highly nonlinear ozone formation in the Houston region and implications for emission controls. J. Geophys. Res. Atmos. 2010, 115, doi: 10.1029/2010JD014435.

37. Zhang, W.; Russell, A.G. The Decoupled Direct Method for Higher-Order Sensitivity Analysis for Particulate Matter in Multidimensional Air Quality Models. In Proceedings of the American Meteorological Society Annual Meeting, Atlanta, GA, USA, January 2010; pp. 17-21.

38. Cohan, D.S.; Tian, D.; Hu, Y.T.; Russell, A.G. Control strategy optimization for attainment and exposure mitigation: Case study for ozone in Macon, Georgia. Environ. Manag. 2006, 38, 451-462.

39. Tagaris, E.; Liao, K.J.; Delucia, A.J.; Deck, L.; Amar, P.; Russell, A.G. Sensitivity of Air Pollution-Induced Premature Mortality to Precursor Emissions under the Influence of Climate Change. Int. J. Environ. Res. Public Health 2010, 7, 2222-2237.

40. Liao, K.J.; Tagaris, E.; Manomaiphiboon, K.; Napelenok, S.L.; Woo, J.H.; He, S.; Amar, P.; Russell, A.G. Sensitivities of ozone and fine particulate matter formation to emissions under the impact of potential future climate change. Environ. Sci. Technol. 2007, 41, 8355-8361.

41. Hu, Y.T.; Odman, M.T.; Russell, A.G. Top-down analysis of the elemental carbon emissions inventory in the United States by inverse modeling using Community Multiscale Air Quality model with decoupled direct method (CMAQ-DDM). J. Geophys. Res. Atmos. 2009, 114, doi: 10.1029/2009JD011987.

42. Mendoza-Dominguez, A.; Russell, A.G. Iterative inverse modeling and direct sensitivity analysis of a photochemical air quality model. Environ. Sci. Technol. 2000, 34, 4974-4981.

43. Napelenok, S.L.; Pinder, R.W.; Gilliland, A.B; Martin, R.V. A method for evaluating spatiallyresolved nox emissions using Kalman filter inversion, direct sensitivities, and space-based $\mathrm{NO}_{2}$ observations. Atmos. Chem. Phys. 2008, 8, 5603-5614.

44. Cohan, D.S.; Koo, B.; Yarwood, G. Influence of uncertain reaction rates on ozone sensitivity to emissions. Atmos. Environ. 2010, 44, 3101-3109.

45. Gao, D.; Stockwell, W.R.; Milford, J.B. Global uncertainty analysis of a regional-scale gas-phase chemical mechanism. J. Geophys. Res. 1996, 101, 9107-9119.

46. Menut, L.; Vautard, R.; Beekmann, M.; Honore, C. Sensitivity of photochemical pollution using the adjoint of a simplified chemistry-transport model. J. Geophys. Res. Atmos. 2000, 105, 15379-15402.

47. Sandu, A.; Daescu, D.N.; Carmichael, G.R.; Chai, T.F. Adjoint sensitivity analysis of regional air quality models. J. Comput. Phys. 2005, 204, 222-252.

48. Hakami, A.; Seinfeld, J.H.; Chai, T.F.; Tang, Y.H.; Carmichael, G.R.; Sandu, A. Adjoint sensitivity analysis of ozone nonattainment over the continental United States. Environ. Sci. Technol. 2006, 40, 3855-3864.

49. Henze, D.K.; Seinfeld, J.H.; Shindell, D.T. Inverse modeling and mapping US air quality influences of inorganic PM2.5 precursor emissions using the adjoint of GEOS-Chem. Atmos. Chem. Phys. 2009, 9, 5877-5903.

50. Hakami, A.; Henze, D.K.; Seinfeld, J.H.; Chai, T.; Tang, Y.; Carmichael, G.R.; Sandu, A. Adjoint inverse modeling of black carbon during the Asian Pacific Regional Aerosol Characterization Experiment. J. Geophys. Res. Atmos. 2005, 110, doi: 10.1029/2004JD005671. 
51. Zhang, L.; Jacob, D.J.; Kopacz, M.; Henze, D.K.; Singh, K.; Jaffe, D.A. Intercontinental source attribution of ozone pollution at western US sites using an adjoint method. Geophys. Res. Lett. 2009, 36, doi: 10.1029/2009GL037950.

52. Kopacz, M.; Mauzerall, D.L.; Wang, J.; Leibensperger, E.M.; Henze, D.K.; Singh, K. Origin and radiative forcing of black carbon transported to the Himalayas and Tibetan Plateau. Atmos. Chem. Phys. 2011, 11, 2837-2852.

53. Sirkes, Z.; Tziperman, E. Finite difference of adjoint or adjoint of finite difference? Mon. Weather Rev. 1997, 49, 5-40.

54. Sandu, A.; Liu, Z. On the properties of discrete adjoints of numerical methods for the advection equation. Int. J. Numer. Methods Fluid. 2008, 56, 769-803.

55. Hopke, P.K. Receptor Modeling in Environmental Chemistry; John Wiley: New York, NY, USA, 1985.

56. Mysliwiec, M.J.; Kleeman, M.J. Source apportionment of secondary airborne particulate matter in a polluted atmosphere. Environ. Sci. Technol. 2002, 36, 5376-5384.

57. Ying, Q.; Krishnan, A. Source contributions of volatile organic compounds to ozone formation in southeast Texas. J. Geophys. Res. Atmos. 2010, 115, doi: 10.1029/2010JD013931.

58. Bhave, P.V.; Pouliot, G.A.; Zheng, M. Diagnostic model evaluation for carbonaceous PM2.5 using organic markers measured in the southeastern US. Environ. Sci. Technol. 2007, 41, 1577-1583.

59. Samaali, M.; Bouchet, V.S.; Moran, M.D.; Sassi, M. Application of a tagged-species method to source apportionment of primary $\operatorname{PM}(2.5)$ components in a regional air quality model. Atmos. Environ. 2011, 45, 3835-3847.

60. Dunker, A.M.; Yarwood, G.; Ortmann, J.P.; Wilson, G.M. Comparison of source apportionment and source sensitivity of ozone in a three-dimensional air quality model. Environ. Sci. Technol. 2002, 36, 2953-2964.

61. ENVIRON International Corporation. User's Guide-Comprehensive Air Quality Model with Extensions Version 4.50; Novato, CA, USA, 2008.

62. Sillman, S.; He, D.Y. Some theoretical results concerning O-3-nox-VOC chemistry and nox-VOC indicators. J. Geophys. Res. Atmos. 2002, 107, doi: 10.1029/2001JD001123.

63. Wagstrom, K.M.; Pandis, S.N.; Yarwood, G.; Wilson, G.M.; Morris, R.E. Development and application of a computationally efficient particulate matter apportionment algorithm in a threedimensional chemical transport model. Atmos. Environ. 2008, 42, 5650-5659.

64. Wang, Z.S.; Chien, C.J.; Tonnesen, G.S. Development of a tagged species source apportionment algorithm to characterize three-dimensional transport and transformation of precursors and secondary pollutants. J. Geophys. Res. Atmos. 2009, 114, doi: 10.1029/2008JD010846.

65. Dennis, R.L.; Bhave, P.V.; Pinder, R.W. Observable indicators of the sensitivity of PM2.5 nitrate to emission reductions-Part II: Sensitivity to errors in total ammonia and total nitrate of the CMAQ-predicted non-linear effect of SO2 emission reductions. Atmos. Environ. 2008, 42, 1287-1300.

66. Carlton, A.G.; Pinder, R.W.; Bhave, P.V.; Pouliot, G.A. To What Extent Can Biogenic SOA be Controlled? Environ. Sci. Technol. 2010, 44, 3376-3380.

67. Baker, K.R.; Foley, K.M. A nonlinear regression model estimating single source concentrations of primary and secondarily formed PM2.5. Atmos. Environ. 2011, 45, 3758-3767. 
68. Zavala, M.; Lei, W.; Molina, M.J.; Molina, L.T. Modeled and observed ozone sensitivity to mobile-source emissions in Mexico City. Atmos. Chem. Phys. 2009, 9, 39-55.

69. Wu, S.L.; Mickley, L.J.; Jacob, D.J.; Logan, J.A.; Yantosca, R.M.; Rind, D. Why are there large differences between models in global budgets of tropospheric ozone? J. Geophys. Res. Atmos. 2007, 112, doi: 10.1029/2006JD007801.

70. Thunis, P.; Rouil, L.; Cuvelier, C.; Stern, R.; Kerschbaumer, A.; Bessagnet, B.; Schaap, M.; Builtjes, P.; Tarrason, L.; Douros, J.; et al. Analysis of model responses to emission-reduction scenarios within the citydelta project. Atmos. Environ. 2007, 41, 208-220.

71. Marr, L.C.; Harley, R.A. Modeling the effect of weekday-weekend differences in motor vehicle emissions on photochemical air pollution in central California. Environ. Sci. Technol. 2002, 36, 4099-4106.

72. Napelenok, S.L.; Foley, K.M.; Kang, D.W.; Mathur, R.; Pierce, T.; Rao, S.T. Dynamic evaluation of regional air quality model's response to emission reductions in the presence of uncertain emission inventories. Atmos. Environ. 2011, 45, 4091-4098.

73. Sillman, S. The use of noy, $\mathrm{H}_{2} \mathrm{O}_{2}$, and $\mathrm{HNO}_{3}$ as indicators for ozone-nox-hydrocarbon sensitivity in urban locations. J. Geophys. Res. Atmos. 1995, 100, 14175-14188.

74. Liu, S.C.; Trainer, M.; Fehsenfeld, F.C.; Parrish, D.D.; Williams, E.J.; Fahey, D.W.; Hubler, G.; Murphy, P.C. Ozone production in the rural troposphere and the implications for regional and global ozone distributions. J. Geophys. Res. Atmos. 1987, 92, 4191-4207.

75. Pinder, R.W.; Dennis, R.L.; Bhave, P.V. Observable indicators of the sensitivity of PM 2.5 nitrate to emission reductions-Part I: Derivation of the adjusted gas ratio and applicability at regulatory-relevant time scales. Atmos. Environ. 2008, 42, 1275-1286.

76. Chow, J.C.; Watson, J.G. Review of PM2.5 and PM10 apportionment for fossil fuel combustion and other sources by the chemical mass balance receptor model. Energy Fuels 2002, 16, 222-260.

77. Reff, A.; Eberly, S.I.; Bhave, P.V. Receptor modeling of ambient particulate matter data using positive matrix factorization: Review of existing methods. J. Air Waste Manag. Assoc. 2007, 57, $146-154$.

78. Schauer, J.J.; Rogge, W.F.; Hildemann, L.M.; Mazurek, M.A.; Cass, G.R. Source apportionment of airborne particulate matter using organic compounds as tracers. Atmos. Environ. 1996, 30, $3837-3855$.

79. Marmur, A.; Park, S.K.; Mulholland, J.A.; Tolbert, P.E.; Russell, A.G. Source apportionment of PM2.5 in the southeastern United States using receptor and emissions-based models: Conceptual differences and implications for time-series health studies. Atmos. Environ. 2006, 40, 2533-2551.

80. Lee, D.; Balachandran, S.; Pachon, J.; Shankaran, R.; Lee, S.; Mulholland, J.A.; Russell, A.G. Ensemble-trained PM2.5 source apportionment approach for health studies. Environ. Sci. Technol. 2009, 43, 7023-7031.

81. Fine, J.; Vuilleumier, L.; Reynolds, S.; Roth, P.; Brown, N. Evaluating uncertainties in regional photochemical air quality modeling. Annu. Rev. Environ. Resour. 2003, 28, 59-106.

82. Bergin, M.S.; Noblet, G.S.; Petrini, K.; Dhieux, J.R.; Milford, J.B.; Harley, R.A. Formal uncertainty analysis of a Lagrangian photochemical air pollution model. Environ. Sci. Technol. 1999, 33, 1116-1126. 
83. Deguillaume, L.; Beekman, M.; Derognat, C. Uncertainty evaluation of ozone production and its sensitivity to emission changes over the Ile-de-France region during summer periods. $J$. Geophys. Res. 2008, 113, doi: 10.1029/2007JD009081.

84. Hanna, S.R.; Lu, Z.; Frey, H.C.; Wheeler, N.; Vukovich, J.; Arunachalam, S.; Fernau, M.; Hansen, D.A. Uncertainties in predicted ozone concentrations due to input uncertainties for the UAM-V photochemical grid model applied to the July 1995 OTAG domain. Atmos. Environ. 2001, 35, 891-903.

85. Digar, A.; Cohan, D.S. Efficient Characterization of Pollutant-Emission Response under Parametric Uncertainty. Environ. Sci. Technol. 2010, 44, 6724-6730.

86. Pinder, R.W.; Gilliam, R.C.; Appel, K.W.; Napelenok, S.L.; Foley, K.M.; Gilliland, A.B. Efficient probabilistic estimates of surface ozone concentration using an ensemble of model configurations and direct sensitivity calculations. Environ. Sci. Technol. 2009, 43, 2388-2393.

87. Tian, D.; Bergin, M.S.; Cohan, D.S.; Napelenok, S.L.; Hu, Y.; Chang, M.E.; Russell, A.G. Uncertainty analysis of ozone formation and response to emission controls using higher-order sensitivities. J. Air Waste Manag. Assoc. 2010, 60, 797-804.

88. Sandu, A.; Zhang, L. Discrete second order adjoints in atmospheric chemical transport modeling. J. Comput. Phys. 2008, 227, 5949-5983.

89. Bergin, M.S.; Milford, J.B. Application of Bayesian Monte Carlo analysis to a Lagrangian photochemical air quality model. Atmos. Environ. 2000, 34, 781-792.

90. Deguillaume, L.; Beekman, M.; Menut, L. Bayesian Monte Carlo analysis applied to regional-scale inverse emission modeling for reactive trace gases. J. Geophys. Res. 2007, 112, doi: 10.1029/2006JD007518.

91. Koo, B.; Wilson, G.M.; Morris, R.E.; Dunker, A.M.; Yarwood, G. Comparison of Source Apportionment and Sensitivity Analysis in a Particulate Matter Air Quality Model. Environ. Sci. Technol. 2009. 43, 6669-6675.

92. Zhang, Y.; Vijayaraghavan, K.; Seigneur, C. Evaluation of three probing techniques in a three-dimensional air quality model. J. Geophys. Res. Atmos. 2005, 110, doi: 10.1029/2004JD005248.

93. Jeffries, H.E.; Tonnesen, S. A comparison of 2 photochemical-reaction mechanisms using mass-balance and process analysis. Atmos. Environ. 1994, 28, 2991-3003.

94. Jang, J.C.C.; Jeffries, H.E.; Tonnesen, S. Sensitivity of ozone to model grid resolution. 2. Detailed process analysis for ozone chemistry. Atmos. Environ. 1995, 29, 3101-3114.

95. Jiang, G.F.; Lamb, B.; Westberg, H. Using back trajectories and process analysis to investigate photochemical ozone production in the Puget Sound region. Atmos. Environ. 2003, 37, 1489-1502.

96. Henderson, B.H.; Jeffries, H.E.; Kim, B.U.; Vizuete, W.G. The influence of model resolution on ozone in industrial volatile organic compound plumes. J. Air Waste Manag. Assoc. 2010, 60, $1105-1117$.

(C) 2011 by the authors; licensee MDPI, Basel, Switzerland. This article is an open access article distributed under the terms and conditions of the Creative Commons Attribution license (http://creativecommons.org/licenses/by/3.0/). 